\title{
Implementing an education program for nurse- midwives focused on early essential care for breast milk expression among mothers of preterm infants
}

Rie Tanaka ( $\nabla$ rie.tanaka@med.teikyo-u.ac.jp )

Teikyo Daigaku https://orcid.org/0000-0001-7481-438X

Shigeko Horiuchi

St Luke's International University: Sei Roka Kokusai Daigaku

\section{Research}

Keywords: Preterm infants, Mothers, Breast milk expression, Obstetric nursing, Education

Posted Date: December 31st, 2020

DOl: https://doi.org/10.21203/rs.3.rs-136755/v1

License: (c) (i) This work is licensed under a Creative Commons Attribution 4.0 International License.

Read Full License 


\section{Abstract}

\section{Background}

Although breastfeeding guidelines for infants admitted to the neonatal intensive care unit (NICU) have been introduced in Japan, these guidelines have not been reflected in practice. To improve this situation, it is important for nurses and nurse-midwives to acquire knowledge of appropriate care. This study examined changes in the knowledge of appropriate care of nurse-midwives after implementing an educational program focused on early essential care for breast milk expression among mothers of preterm infants.

\section{Methods}

This before-after study using a single group enrolled 36 nurse-midwives in one perinatal medical center. The educational program content included nurses' roles in early essential care for milk expression and the necessary care to promoting breast milk production among mothers of preterm infants. The nursemidwives' knowledge and attitude on care were investigated three months before (pre-1), just before (pre2), just after (post-1), and three months after (post-2) the program. The nurse-midwives' care implementation was investigated at pre-1, pre-2, and post-2. During this time, 11 mothers (before: 7, after: 4) reported the status of milk expression for 10 days after birth.

\section{Results}

The mean knowledge scores of the nurse-midwives at post- 1 and post- 2 were significantly higher than that at pre-2 (post-1: $p<0.001$, post-2: $p<0.001$ ). The attitude on care scores at post-1 and post-2 were significantly higher than that at pre-2 (post- $1: p<0.001$, post-2: $p=0.010$ ). The care implementation score at post-2 was significantly higher than that at pre-2 in eight items (e.g., Q7 Explain about the effect of initiating milk expression early and assist mothers in it). However, the educational program did not cause any changes in the mothers' initiation and frequency of milk expression, and breast milk volume after birth.

\section{Conclusions}

The significant increases in the knowledge, attitude on care, and care implementation scores of the nursemidwives suggest the beneficial effects of the educational program. Further detailed examination of the effects of the program on nurses and nurse-midwives, and identification of methods to reduce barriers to the practice of best evidence in the clinical setting are warranted to improve mothers' status of milk expression.

\section{Full Text}

This preprint is available for download as a PDF. 
Figures

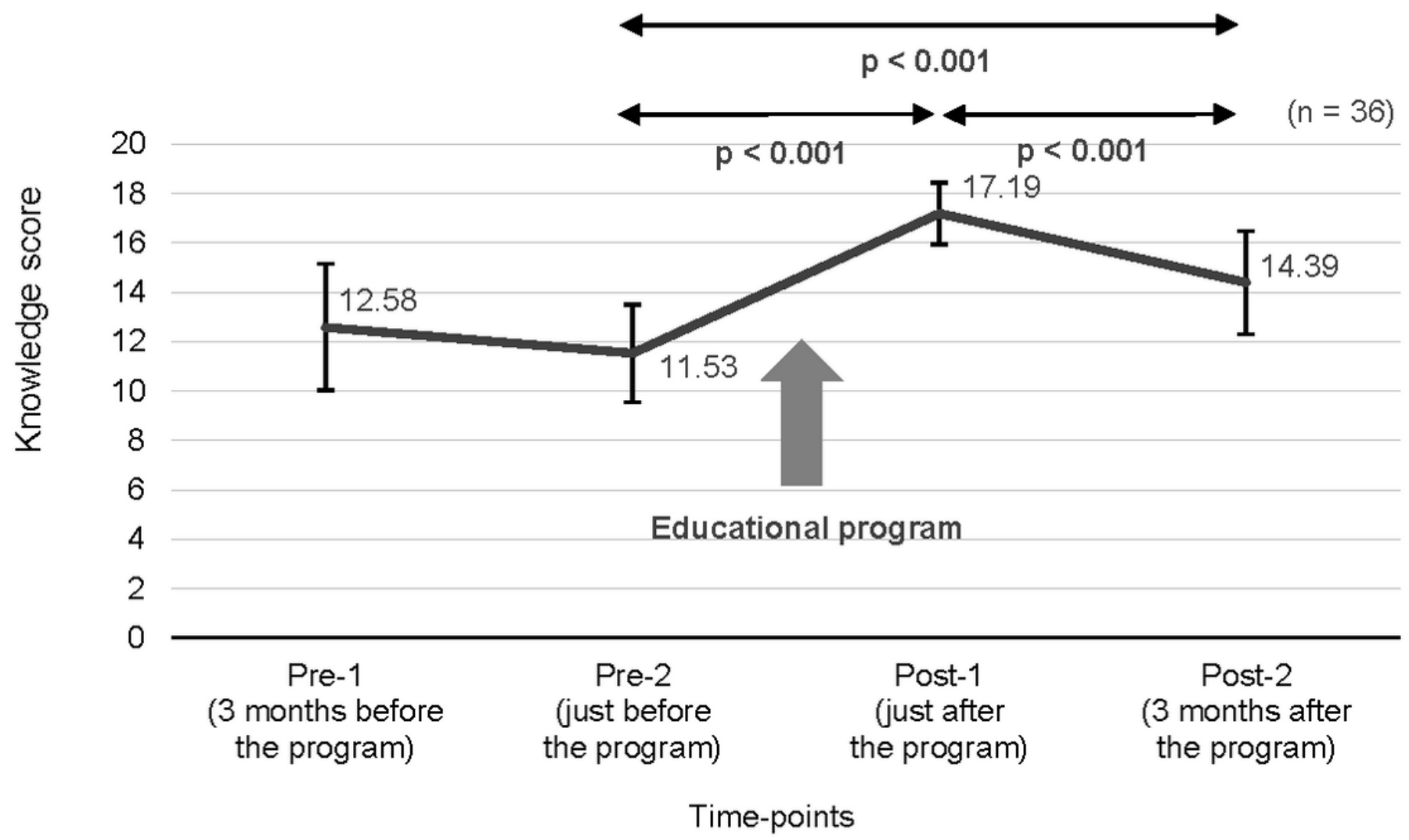

Figure 1

Knowledge scores (mean and SD) of nurse-midwives at four time-points 


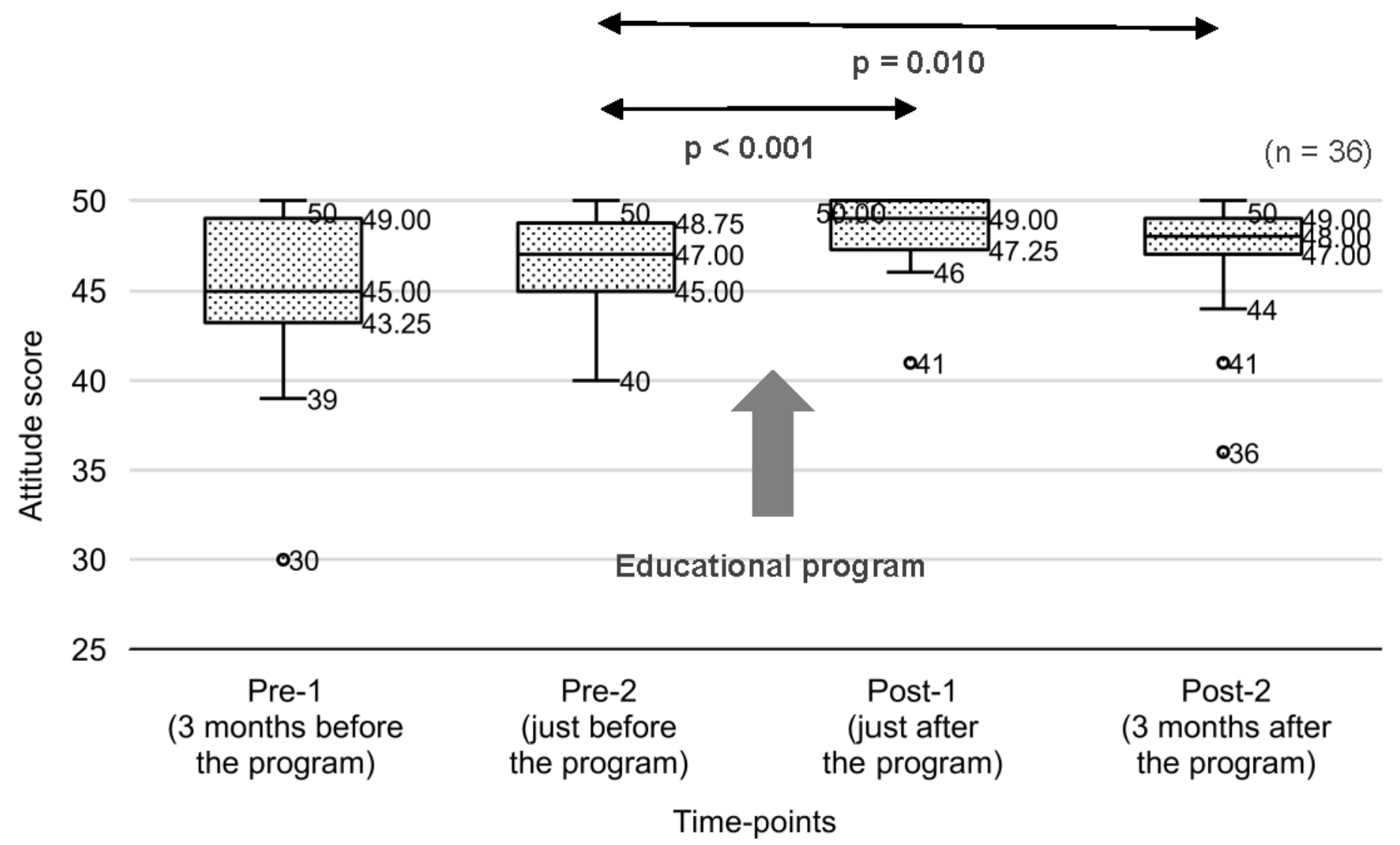

Figure 2

Attitude scores (median and IQR) of nurse-midwives at four time-points 


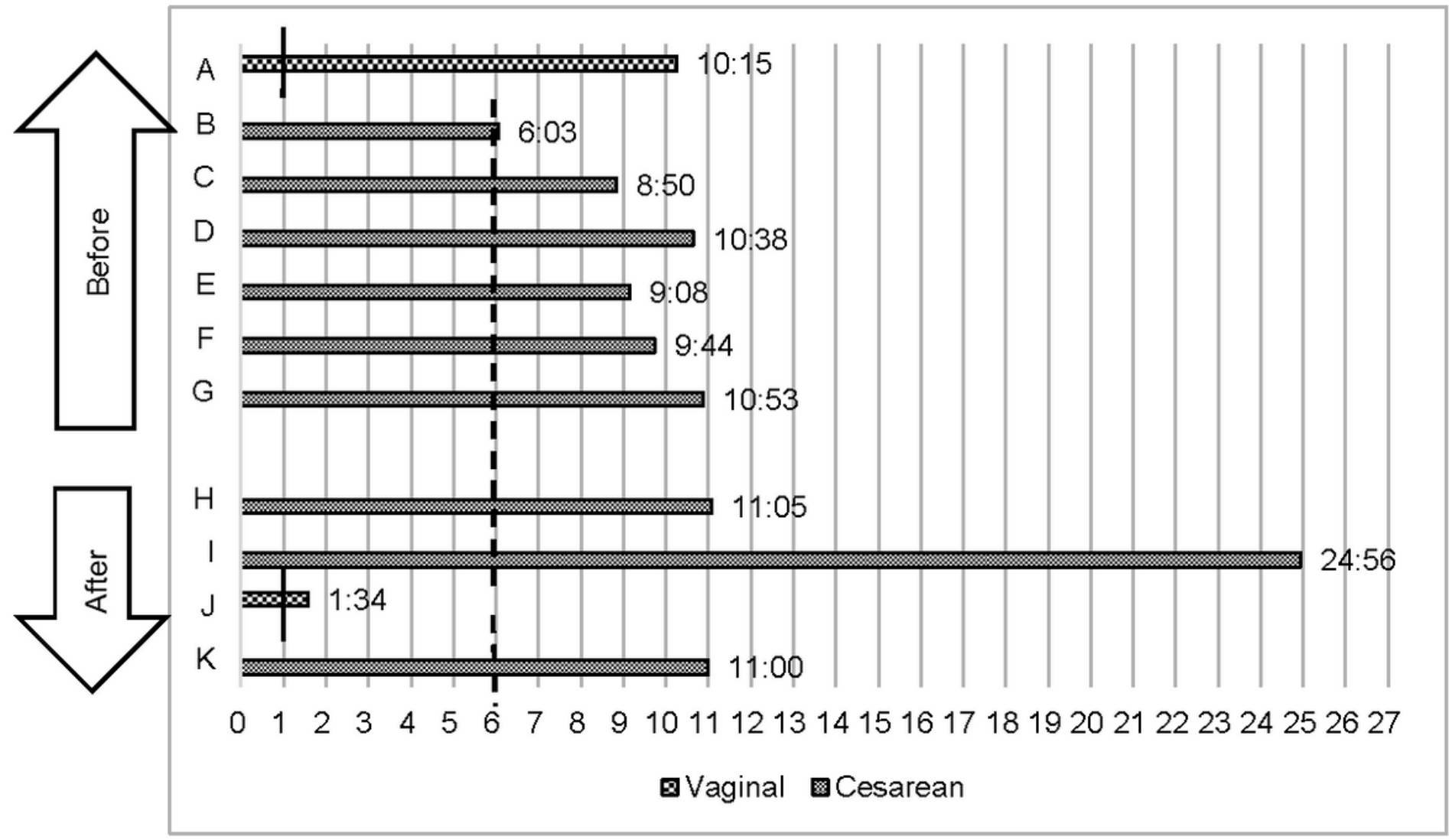

Figure 3

Number of hours before initiation of milk expression in mothers 


\begin{tabular}{|c|c|c|c|c|c|c|c|c|c|c|c|c|}
\hline \multicolumn{2}{|l|}{ Day } & 1 & 2 & 3 & 4 & 5 & 6 & 7 & 8 & 9 & 10 & $\begin{array}{c}\text { Mean } \\
\text { frequency }\end{array}$ \\
\hline \multirow{7}{*}{ Before } & A & & & & & & & & & & & 6.8 \\
\hline & $B$ & & & unknown & & & & & & & & 8.7 \\
\hline & C & & & & & & & & & & & 6.4 \\
\hline & D & & & & & & & & & & & 6.1 \\
\hline & $E$ & & & & & & & & & & & 7.8 \\
\hline & $F$ & & & & & & & & & & & 6.5 \\
\hline & G & & & & & & & & & & & 5.5 \\
\hline \multirow{4}{*}{ After } & $\mathrm{H}$ & & & & & & & & & & & 7.3 \\
\hline & I & & & & & & & & & & & 7.1 \\
\hline & J & & & & & & & & & & & 5.0 \\
\hline & K & & & & & & & & & & & 4.2 \\
\hline
\end{tabular}

Seven times or more per day

Figure 4

Frequency of milk expression per day for 10 days after birth by each mother 